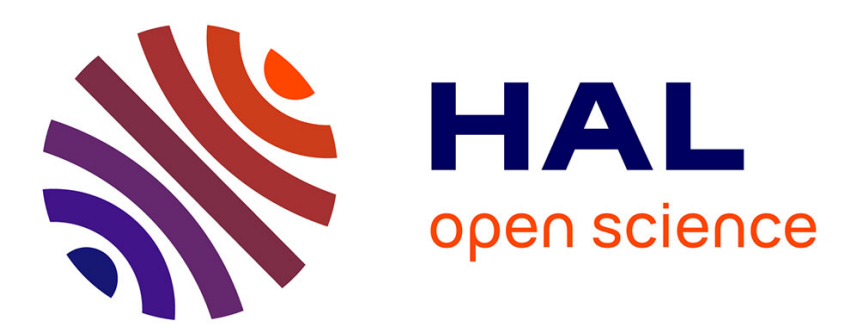

\title{
Tetraalkylammonium Functionalized Hydrochars as Efficient Supports for Palladium Nanocatalysts
}

Tiago Duarte, Isabelle Favier, Christian Pradel, Luísa Martins, Ana Carvalho, Daniel Pla, Montserrat Gómez

\section{- To cite this version:}

Tiago Duarte, Isabelle Favier, Christian Pradel, Luísa Martins, Ana Carvalho, et al.. Tetraalkylammonium Functionalized Hydrochars as Efficient Supports for Palladium Nanocatalysts. ChemCatChem, 2020, 12 (8), pp.2295-2303. 10.1002/cctc.201902305 . hal-03011369

\author{
HAL Id: hal-03011369 \\ https://hal.science/hal-03011369
}

Submitted on 18 Nov 2020

HAL is a multi-disciplinary open access archive for the deposit and dissemination of scientific research documents, whether they are published or not. The documents may come from teaching and research institutions in France or abroad, or from public or private research centers.
L'archive ouverte pluridisciplinaire HAL, est destinée au dépôt et à la diffusion de documents scientifiques de niveau recherche, publiés ou non, émanant des établissements d'enseignement et de recherche français ou étrangers, des laboratoires publics ou privés. 


\section{Tetraalkylammonium functionalized hydrochars as efficient supports for palladium nanocatalysts}

Tiago A. G. Duarte,${ }^{[a, b]}$ Isabelle Favier, ${ }^{[c]}$ Christian Pradel, ${ }^{[c]}$ Luísa M. D. R. S. Martins, ${ }^{[a]}$ Ana P. Carvalho, ${ }^{*[b]}$ Daniel Pla, ${ }^{*[c]}$ and Montserrat Gómez ${ }^{*[c]}$

[a] Mr. T. A. G. Duarte, Prof. L. M. D. R. S. Martins

Centro de Química Estrutural

Instituto Superior Técnico, Universidade de Lisboa

Av. Rovisco Pais, 1049-001 Lisboa, Portugal

[b] Mr. T. A. G. Duarte, Prof. A. P. Carvalho

Centro de Química e Bioquímica e Centro de Química Estrutural

Faculdade de Ciências, Universidade de Lisboa

Campo Grande, 1749-016 Lisboa, Portugal

E-mail: apcarvalho@fc.ul.pt

[c] Dr. I. Favier, Mr. C. Pradel, Dr. D. Pla, Prof. M. Gómez

Laboratoire Hétérochimie Fondamentale et Appliquée

Université de Toulouse 3 - Paul Sabatier, CNRS UMR 5069

118 route de Narbonne, 31062 Toulouse Cedex 9, France

E-mails: pla@lhfa.fr, gomez@chimie.ups-tlse.fr

Supporting information for this article is given via a link at the end of the document and contains general experimental procedures, materials, and characterization of hydrochar supports and nanomaterials (Boehm titration, elemental analysis, FTIR, SEM, TEM, XPS), and selected organic compounds $\left({ }^{1} \mathrm{H}\right.$ and ${ }^{13} \mathrm{C}$ NMR)

\begin{abstract}
With the aim of preparing bio-sourced supports with enhanced properties in catalysis, we devised an original strategy allowing the immobilization of metal nanoparticles. Thus, sizecontrolled hydrochars with a high degree of hydroxyl functionalities, from both neat sucrose or modified with acrylic acid (10 wt. \%), were derivatized with ether linkers containing ammonium groups. These non-porous carbon-based materials were used as suitable supports for the immobilization of palladium nanoparticles. The catalytic materials were synthesized by reduction of $\mathrm{Pd}(\mathrm{OAc})_{2}$ to $\mathrm{Pd}(0)$ under $\mathrm{H}_{2}$ atmosphere in the presence of the corresponding hydrochar, and fully characterized by standard methods. Among the different hydrochar-supported palladium materials, those functionalized with tetraalkylammonium groups afforded heterogeneous catalysts, exhibiting high activity in hydrogenations of different types of substrates (alkynes, alkenes, and carbonyl and nitro derivatives). The most efficient catalyst was recycled up to ten runs without loss of catalytic behavior, in agreement with the unchanged catalytic materials after catalysis [Transmission Electron Microscopy (TEM) analyses] and the lack of metal leaching in the extracted organic [no palladium detected by Inductively Coupled Plasma-Atomic Emission Spectrometry (ICP-AES)]; these systems exhibited enhanced recyclability properties as compared to commercial $\mathrm{Pd} / \mathrm{C}$ catalyst.
\end{abstract}

\section{Introduction}

Palladium nanoparticle-based catalysts play a pivotal role in $\mathrm{H}_{2-}$ based reactions, such as hydrodehalogenations of haloarenes ${ }^{[1]}$ and the reduction of unsaturated substrates, ${ }^{[2]}$ including oxidized nitrogen derivatives, ${ }^{[2 \mathrm{a}, 3]}$ especially for the production of anilines at industrial scale. ${ }^{[4]}$ This versatile reactivity offers great potential towards contaminated water/soil remediation via degradation of pollutants ${ }^{[5]}$ and environmentally friendly processes by means of selective catalytic reduction approaches precluding $\mathrm{NO}_{x}$ emissions. ${ }^{[6]}$ In this context, the synthesis of palladium nanoparticles (PdNPs) has been intensively studied over the last decades, with particular focus on finely control size, composition and morphology of the as-prepared particles, having these key parameters a direct impact on catalytic activity. ${ }^{[7]}$ However, the cost and low abundance of noble metals in the Earth's crust demand for robust immobilization strategies for the synthesis of heterogeneized catalysts encompassing efficient recycling. Since the re-use of the these high-value metal particles is a major concern from economic and environmental point of view, different approaches to prepare reusable PdNPs have been reported in the literature, such as their immobilization in liquid phases, e.g. ionic liquids, ${ }^{[8]}$ water $^{[9]}$ and polyols, ${ }^{[1-2,10]}$ as well as on different solid supports, e.g. mesoporous silica, ${ }^{[11]}$ zeolites, ${ }^{[12]}$ clays, ${ }^{[13]}$ polymers, ${ }^{[14]}$ metal-organic frameworks ${ }^{[15]}$ or carbonbased materials. ${ }^{[7,16]}$ Particularly concerning the latter materials, carbon nanospheres, ${ }^{[17]}$ nanotubes, ${ }^{[3 a, 18]}$ halloysite-hydrochar nanocomposites ${ }^{[19]}$ and graphene oxide, ${ }^{[20]}$ are among the most used.

In the search of new materials with enhanced properties, hydrothermal carbonization (HTC) methods affording nonporous and spherically-shaped hydrochars enriched with sulfonic, ${ }^{[21]}$ amino, ${ }^{[22]}$ aminopropyltriethoxysilane ${ }^{[23]}$ or ethylenediamino groups have been reported involving renewable biomass as carbon precursors. ${ }^{[24]} \mathrm{Up}$ to now, the presence of multiple functional groups on the surface of the hydrochars has limited their chemoselective functionalization. ${ }^{[25]}$ A glutaraldehyde cross-linked polyethylene imine strategy has successfully been applied for the derivatization of hydrochars, ${ }^{[26]}$ but more efforts are required for their selective functionalization. Hitherto, raw carbonaceous materials from biomass have been used as supports for palladium-based nanocatalysts showing catalytic activity ${ }^{[16-17]}$ for both adsorption and hydrodehalogenation of chlorinated hydrocarbon pollutants. ${ }^{[27]}$ In this context, we envisioned to study the selective derivatization of free hydroxyl groups on the carboxylic acid-free hydrochars via ether bond formation to graft a tetralkylammonium tail, with the purpose of obtaining supports containing both robust linkers (high chemical stability of ether groups) and efficient metal 
nanoparticles stabilizers (ammonium moieties inducing electrostatic stabilization).

Taking into account our experience in the synthesis of both hydrochars ${ }^{[28]}$ and metal-based nanocatalysts, ${ }^{[29]}$ we have prepared functionalized supports for the immobilization of PdNPs, given the promising properties of raw hydrochars as supports for catalytic materials. ${ }^{[30]}$ Herein, we describe a comparative study of alkylammonium functionalized hydrochars versus their parent hydrochars as supports for the immobilization of palladium nanoparticles.

\section{Results and Discussion}

\section{Synthesis and characterization of hydrochar-based supports}

Carbon materials HCh-A and HCh-B were prepared as previously described via hydrothermal treatment of both neat sucrose and sucrose supplemented with acrylic acid (10 wt\%), respectively, in moderate yields $(32-40 \%$, see Figure S1 in the Supporting Information). ${ }^{[31]}$

Boehm titration analyses revealed the presence of carboxylic acid, lactone, and phenol functionalities, being phenols the most abundant groups (57 and $54 \%$ of the total number of surface functional groups for $\mathbf{H C h}-\mathbf{A}$ and $\mathbf{H C h}-\mathbf{B}$, respectively; see Table $\mathrm{S} 1$ in the Supporting Information).

Robust chemical functionalization of supports is crucial in the rational conception of stable materials that can resist the conditions required for catalytic applications. Actually, the stability of the catalytic materials is a key enabling factor towards high turnover numbers and their enhanced reusability properties. In particular, unbranched ether bond linkages present high chemical stability and their cleavage can only take place under strongly acidic or extremely basic conditions. ${ }^{\left[{ }^{[2]}\right.}$ To conceive a selective functionalization strategy via ether bond formation, the carboxylic acid residues on the hydrochars surface should be removed. Thus, an optimized thermal treatment $\left(340{ }^{\circ} \mathrm{C}\right.$ for 30 $\mathrm{min}$ ) of $\mathbf{H C h}-\mathbf{A}$ and $\mathbf{H C h}-\mathbf{B}$ led to their complete decarboxylation, resulting in the new hydrochars $\mathbf{H C h}-\mathbf{C}$ and $\mathbf{H C h}-\mathbf{D}$, respectively (Figure 1). The thermal procedure enabled not only to remove the carboxylic acid residues, but also minimize the amount of lactonic groups present in $\mathbf{H C h}-\mathbf{A}$ and $\mathbf{H C h}-\mathbf{B}$ (Figure 2). Even though the four hydrochars are acid materials, a moderate increase of the $\mathrm{pH}$ at the point of zero charge $\left(\mathrm{pH}_{\mathrm{PzC}}\right)$ was observed for the thermally treated materials, HCh-C and HCh-D (see Table S1 in the Supporting Information), in agreement with the decrease of the acid groups (determined by Boehm titration). Fourier Transform Infrared (FTIR) spectra of HCh-A and HCh-B presented strong absorption bands in the range of 1585-1600 $\mathrm{cm}^{-1}$ corresponding to aromatic $\mathrm{C}=\mathrm{C}$ bond stretching. The presence of alcohols (absorption bands at 3200-3640 and 1049$1276 \mathrm{~cm}^{-1}$ ) and carboxylic acids (bands in the region 3200-3640, ca. 1690 and $1000-1250 \mathrm{~cm}^{-1}$ ) was also evidenced. ${ }^{[3]}$ As expected, the bands assigned to carboxylic acids are more intense in the case of HCh-B (see Figure S2 in the Supporting Information).

The morphology of HCh-C and HCh-D did not exhibit significant modifications in comparison to the untreated hydrochars $\mathbf{H C h}-\mathbf{A}$ and $\mathbf{H C h}-\mathbf{B}$, as observed by SEM micrographs (Figure 3 vs Figure $\mathbf{S} 1$ in the Supporting Information). In accordance with the Boehm titration results, HCh-D obtained by thermal treatment showed a decrease of the IR absorption bands associated to carboxylic groups, especially the band assigned to the $\mathrm{C}=\mathrm{O}$ bond stretching (Figure 4).

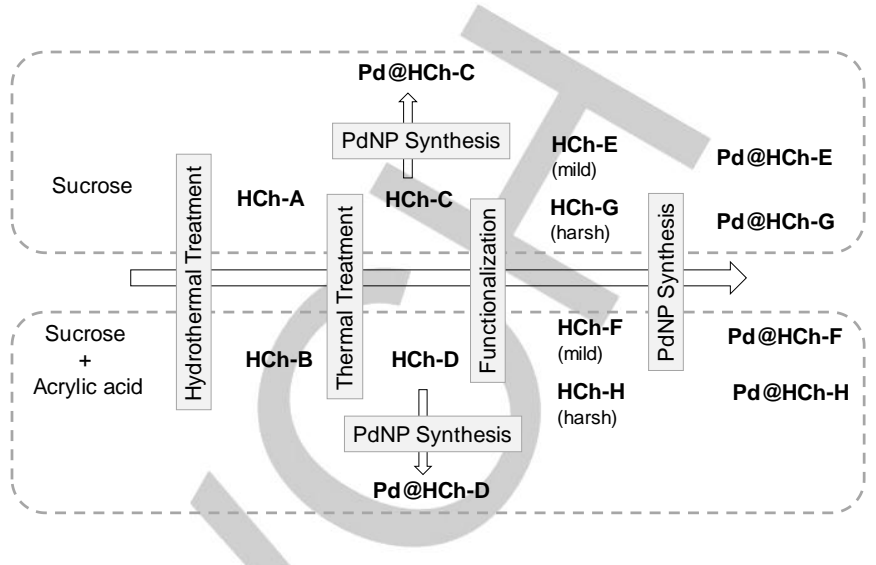

Figure 1. Synthesis of functionalized hydrochars and Pd@hydrochar-based catalytic materials.

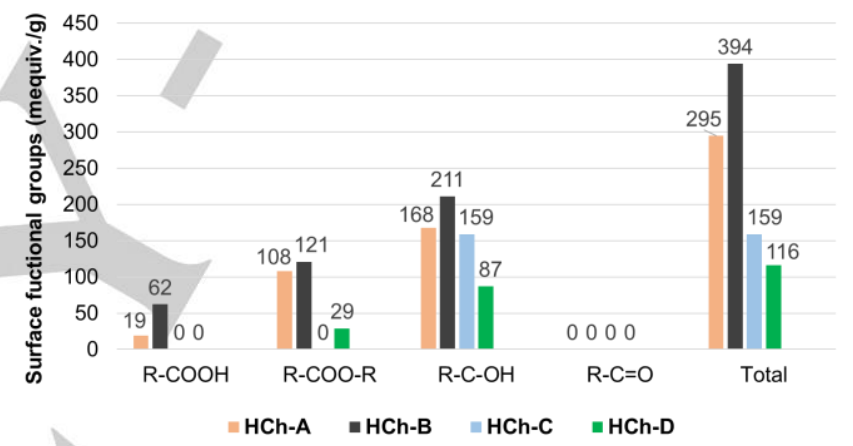

Figure 2. Boehm titration analyses of hydrochars $\mathrm{HCh}-\mathrm{A}, \mathrm{HCh}-\mathrm{B}, \mathrm{HCh}-\mathrm{C}$, and HCh-D.

In terms of porosity, the thermally treated HCh-C and HCh-D presented low $\mathrm{N}_{2}$ uptake which correlated with the non-porous nature of the starting hydrochars $\mathbf{H C h}-\mathbf{A}$ and $\mathbf{H C h}-\mathbf{B}$, respectively. The specific surface area $\left(7 \mathrm{~m}^{2} \mathrm{~g}^{-1}\right)$ and total pore volume $\left(0.01 \mathrm{~cm}^{3} \mathrm{~g}^{-1}\right)$ were determined for $\mathrm{HCh}-\mathrm{D}$ which matched with the values of the parent hydrochar $\mathbf{H C h}-\mathbf{B} ;{ }^{[31]}$ however the negligible porosities of $\mathbf{H C h}-\mathbf{C}$ and $\mathbf{H C h}-\mathbf{A}$ could not be quantified by the analytical method employed. ${ }^{[34]}$ The volume of HCh-D results from the large porosity created by the aggregation of small hydrochar particles and proves that the thermal treatment did not affect the surface area and total pore volume characteristics of the material (Figure 3).

A selective functionalization of hydroxyl groups was then envisaged via ether bond formation through different strategies compatible with the nature of the supports. Reaction of hydrochars with sodium hydride in an aprotic solvent (DMF) was an efficient treatment for the deprotonation of the hydroxyl groups into alkoxides, sequentially reacting with the bromoalkylammonium bromide 1 via a nucleophilic substitution reaction (Figure 5). 
HCh-C

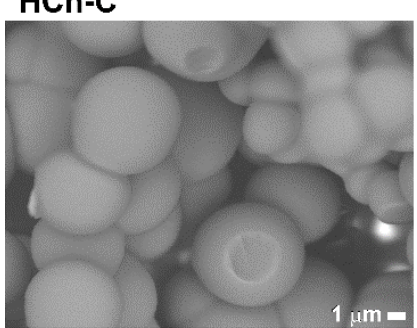

HCh-E

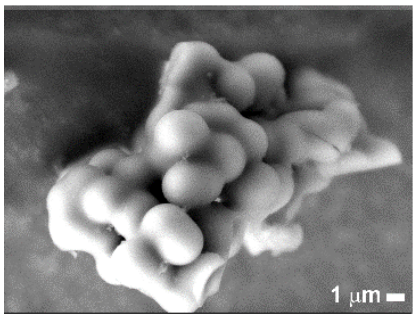

HCh-G

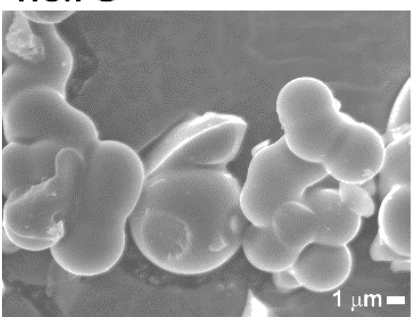

HCh-D

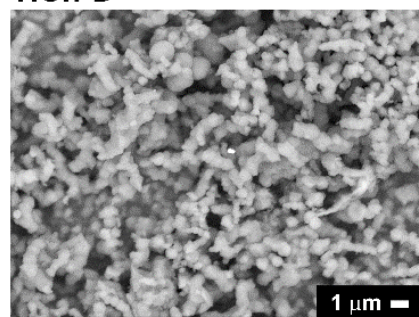

HCh-F

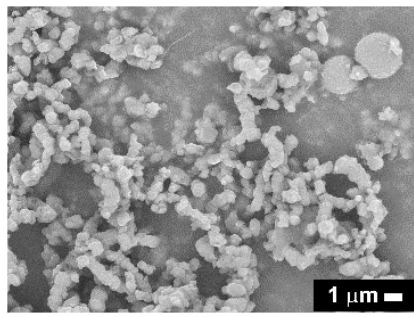

$\mathrm{HCh}-\mathrm{H}$

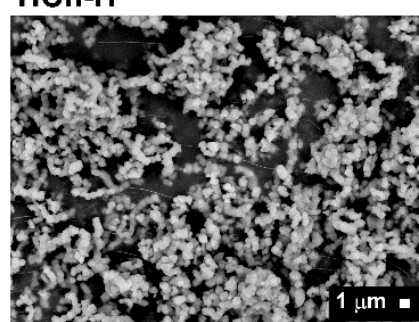

Figure 3. SEM micrographs of hydrochars obtained by thermal treatment (HCh-C and HCh-D) and their functionalization via ether linkages (HCh-E and HCh-G from $\mathbf{H C h}-\mathbf{C}$; $\mathbf{H C h}-\mathbf{F}$ and $\mathbf{H C h}-\mathbf{H}$ from $\mathbf{H C h}-\mathbf{D})$. Note: for $\mathbf{H C h}-\mathbf{H}$, image magnification is $3,000 \mathrm{x}$; for the other images, $5,000 \mathrm{x}$.

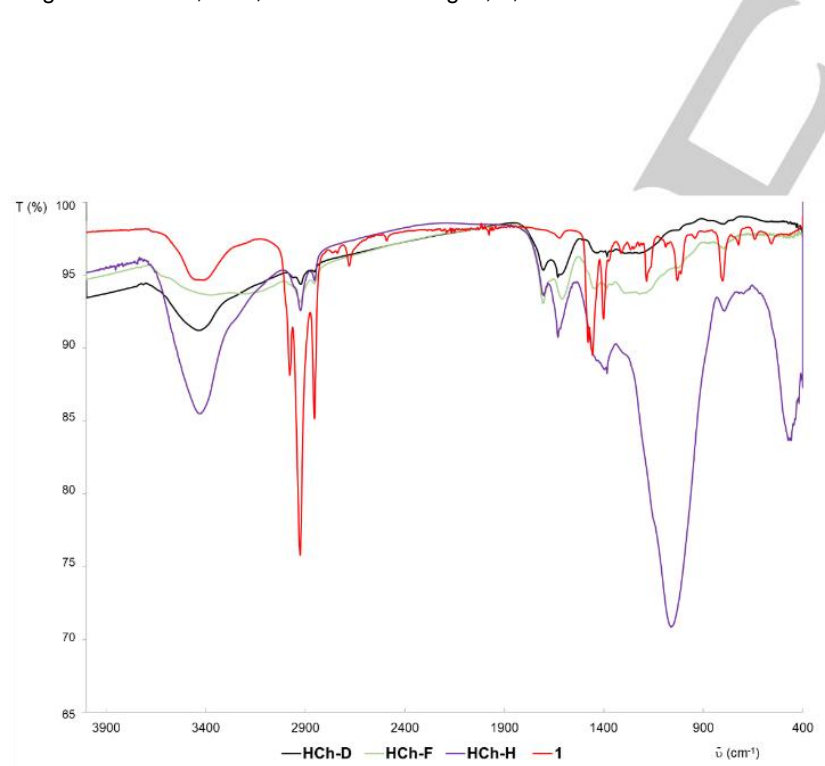

Figure 4. FTIR spectra ( $\mathrm{KBr}$ pellets) of $\mathbf{H C h}-\mathrm{D}, \mathbf{H C h}-\mathbf{F}, \mathbf{H C h}-\mathbf{H}$, and the bromoalkylammonium 1.

Based on the quantified hydroxyl functional groups (determined by Boehm titration), 2 and 20 equiv. of $\mathrm{NaH}$ were used (Figure 5). In both cases, $\mathrm{NaH}$ was added to a suspension of the corresponding hydrochar (HCh-C or HCh-D) suspended in dry DMF under Ar; the reaction mixture was then heated to $90{ }^{\circ} \mathrm{C}$ for the specified time $(40 \mathrm{~min}$ or $6 \mathrm{~h}$ ). For the mild strategy, the ammonium salt 1 was added directly to the reaction mixture. However, when harsher reaction conditions were employed, the supernatant was filtered out under Ar after the basic treatment, and then the alkoxide-based hydrochar was re-suspended in a solution containing 1 in order to avoid concomitant degradation reactions. In both cases, the alkylation reactions were run at 90 ${ }^{\circ} \mathrm{C}$ for $16 \mathrm{~h}$ under $\mathrm{Ar}$. The resulting solids were fully characterized by SEM, elemental analysis, solid state NMR, and FTIR.

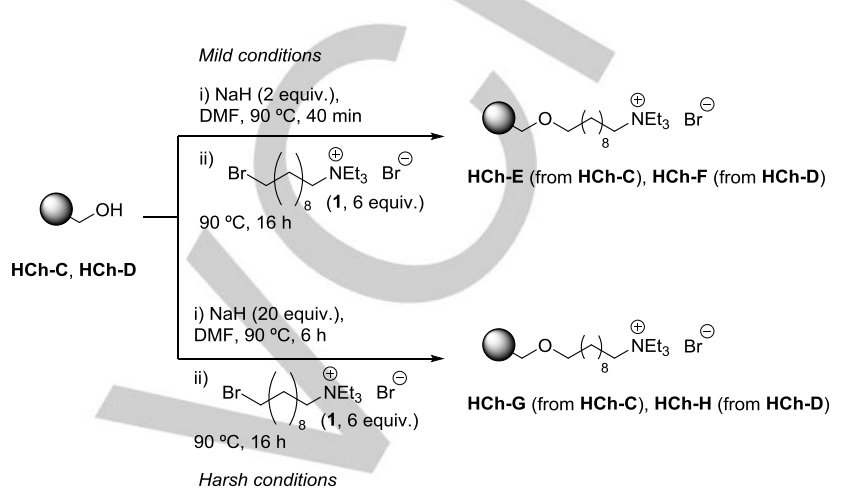

Figure 5. Mild and harsh strategies for $\mathbf{H C h}-\mathbf{C}$ and $\mathbf{H C h}-\mathbf{D}$ functionalization via ether bond formation, leading to $\mathbf{H C h}-\mathbf{E}$ and $\mathbf{H C h}-\mathbf{G}$ (from $\mathbf{H C h}-\mathbf{C}$ ), and $\mathbf{H C h}-\mathbf{F}$ and $\mathbf{H C h}-\mathbf{H}$ (from HCh-D).

SEM micrographs before and after functionalization revealed that the hydrochar derived from neat sucrose $(\mathbf{H C h}-\mathbf{C})$ was much more sensitive to basic treatments (under both mild and harsh conditions, $\mathbf{H C h}-\mathbf{E}$ and $\mathbf{H C h}-\mathbf{G}$, respectively) than the one containing acrylic acid as additive (HCh-D), observing broken spheres and debris for HCh-E and HCh-G (Figure 3). In contrast, HCh-D presenting smaller fused nanospheres was functionalized under both basic conditions preserving the morphology, leading to $\mathbf{H C h}-\mathbf{F}$ (mild conditions) and $\mathbf{H C h}-\mathbf{H}$ (harsh conditions) (Figure 3). After these observations, we focused on the characterization of $\mathbf{H C h}-\mathbf{F}$ and $\mathbf{H C h}-\mathbf{H}$.

In contrast to FTIR spectra of the starting materials (the ammonium salt $\mathbf{1}$ and $\mathbf{H C h}-\mathbf{D}), \mathbf{H C h}-\mathbf{F}$ and $\mathbf{H C h}-\mathbf{H}$ exhibited a more intense band at $c a .1060 \mathrm{~cm}^{-1}$ that was attributed to the $\mathrm{C}_{-}$ $O$ bond stretching of ether groups, in agreement with the reported data (C-O bond stretching appears at $1150-1085 \mathrm{~cm}^{-1}$ for acyclic ethers) (Figure 4). ${ }^{[5]}$ Extended reaction times employed for the preparation of $\mathbf{H C h}-\mathbf{H}$ can yield ether groups on the surface without incorporating ammonium linkers. Accordingly, the nitrogen content determined by elemental analysis (see Table S2 in the Supporting Information) for both functionalized materials was similar $(0.88 \%$ for $\mathbf{H C h}-\mathbf{F}$ and $0.92 \%$ for $\mathbf{H C h}-\mathbf{H})$; for the non-functionalized material $\mathbf{H C h}-\mathbf{D}$, the nitrogen content was practically negligible $(0.08 \%)$.

\section{Synthesis and characterization of Pd@hydrochar-based supports}

We prepared zero-valent PdNPs supported on the different hydrochars following a one-step procedure. $\mathrm{Pd}(\mathrm{OAc})_{2}$ was reduced under hydrogen pressure in the presence of the corresponding hydrochar (HCh-C to HCh-H) (Figure 6), leading to materials containing the metal particles dispersed on the support surface as evidenced by Transmission Electron Microscopy (TEM) (Figure 7). 


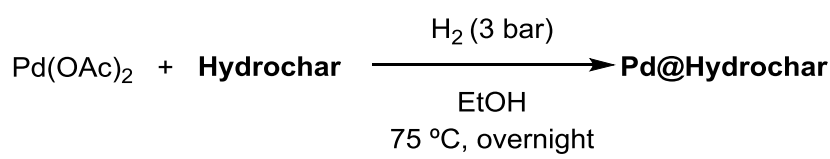

Hydrochar $=\mathrm{HCh}-\mathrm{C}$ to $\mathrm{HCh}-\mathrm{H}$

Figure 6. One-step methodology for the synthesis of PdNPs supported on hydrochar-based supports (Pd@Hydrochar).

We also tested a sequential two-step methodology, preparing first colloidal PdNPs in glycerol under hydrogen pressure using polyvinylpyrrolidone (PVP) as stabilizer based on our previously reported approach, ${ }^{[29 c]}$ followed by physisorption of these preformed PdNPs on HCh-F. In this case, PVP competes with the hydrochar as stabilizer and only partial immobilization of PdNPs on the support was achieved as observed by TEM (see Figure $\mathrm{S} 3$ in the Supplementary Information).

\section{Pd@HCh-C}

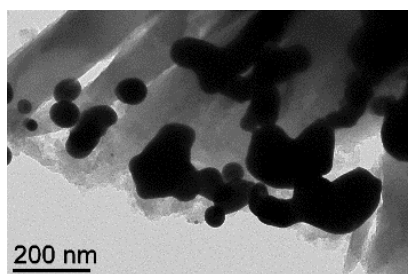

\section{Pd@HCh-E}

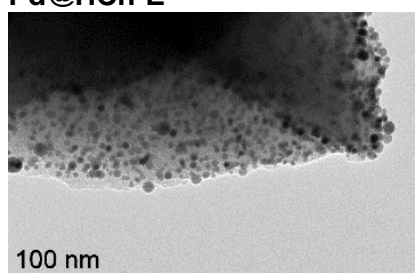

\section{Pd@HCh-G}

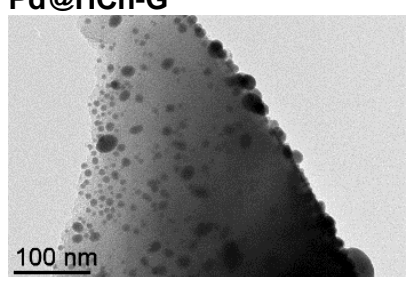

\section{Pd@HCh-D}

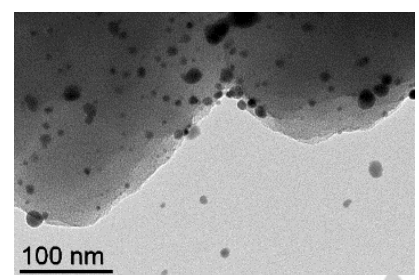

\section{Pd@HCh-F}

\section{Pd@HCh-H}

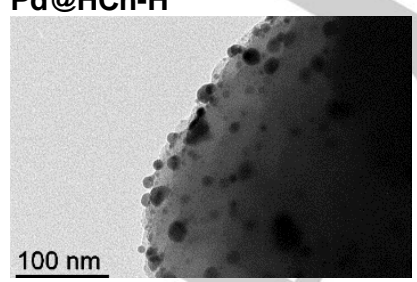

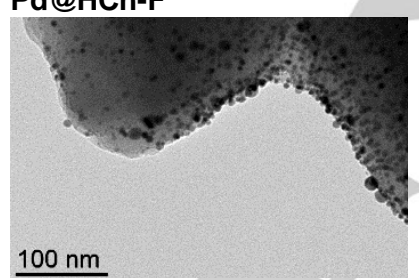

Figure 7. TEM images of hydrochar-supported PdNPs (Pd@HCh-C to Pd@HCh-H)

Concerning the one-step methodology (Figure 6), the influence of the nature of the support resulted crucial for the deposition of PdNPs on hydrochars (Figure 7). For the materials obtained after thermal treatment presenting hydroxyl groups on the surface (HCh-C and HCh-D), large agglomerates of palladium were observed for Pd@HCh-C, whereas supported and unsupported nanoparticles were detected for Pd@HCh-D, showing a large size distribution $(6.7 \pm 2.8 \mathrm{~nm})$. Thus, we can conclude that the interaction of the hydroxyl groups on the surface is not strong enough to immobilize the nanoparticles on the carbonaceous support in an efficient manner. In contrast, for the tetralkylammonium functionalized hydrochars under both mild (Pd@HCh-E and Pd@HCh-F) and harsh (Pd@HCh-G and Pd@HCh-H) conditions, PdNPs were efficiently adsorbed on the supports. This might be due to the electrostatic interaction of the nanoparticles with the ammonium groups on the surface of the hydrochars, as this type of interaction is well-known to kinetically stabilize metal nanoparticles avoiding their agglomeration. ${ }^{[36]}$ The particle size distribution of those PdNPs prepared from supports functionalized under mild conditions were more homogeneous [Pd@HCh-E (6.6 \pm 2.2 nm) and Pd@HCh-F (5.4 $\pm 1.5 \mathrm{~nm})]$ than those obtained under harsher conditions [Pd@HCh-H (6.8 $\pm 2.5 \mathrm{~nm})$ and Pd@HCh-G]. In particular, two populations of PdNPs were present in Pd@HCh-G [ca. 5.0 nm $(42 \%)$ and $8.0 \mathrm{~nm}(58 \%)$, see Figure S4 in the Supporting Information]. Besides, given the degradation of acrylic acid-free supports under basic conditions (see above Figure 3), Pd@HCh-E and Pd@HCh-G were discarded for further reactivity studies. Overall, Pd@HCh-F presented the best dispersion and the smallest PdNPs among the series of functionalized materials (see Figure S4 in the Supporting Information for further details).

X-ray Photoelectron Spectroscopy (XPS) analysis of Pd-based nanomaterials derived from acrylic acid hydrochars (Pd@HCh-D, Pd@HCh-F, and Pd@HCh-H) served to prove the presence of $\mathrm{Pd}(0)$ as well as the elements coming from the support [C, O and $\mathrm{Br}$ (Figure 8 for Pd@HCh-F) and Table S3 in the Supporting Information]. Nitrogen could not be detected by this technique due to its low content $(0.43 \%$, determined by elemental analysis), below the limit of detection of the XPS technique (ca. $0.5 \%$ ).
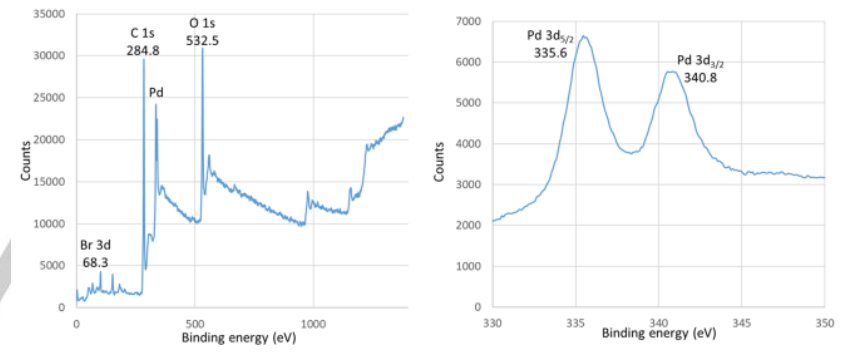

Figure 8. XPS analysis for Pd@HCh-F: survey spectrum (left) and highresolution spectrum in the $\mathrm{Pd} 3 \mathrm{~d}$ binding energy region (right).

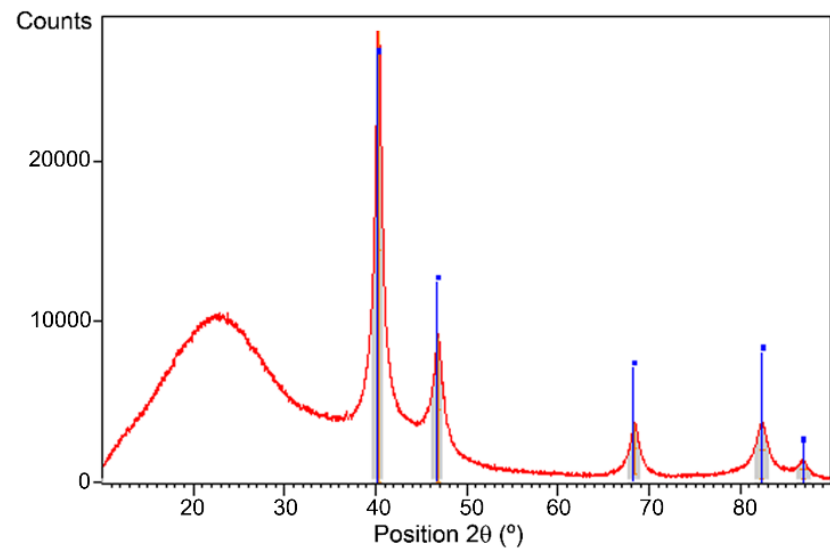


Figure 9. Powder X-ray diffractogram corresponding to Pd@HCh-F (red), showing the reference patterns for fcc $\operatorname{Pd}(0)$ structure (blue).

Powder X-Ray Diffraction (PXRD) of Pd@HCh-F revealed the presence of crystalline $\mathrm{Pd}(0)$ showing the expected fcc structure (Figure 9). A broad band centered on $24^{\circ}(2 \theta)$ points to the presence of amorphous material due to the carbon-based support.

With the aim of determining the support structure, Raman analyses were carried for HCh-D, HCh-F, Pd@HCh-D, and Pd@HCh-F. However, any absorption corresponding to graphite (G) or diamond (D) bands was observed, as reported for sucrose-derived biochars obtained by pyrolysis at relative low temperature $\left(215^{\circ} \mathrm{C}\right) . .^{[37]}$

In order to evidence the functionalization of the support, solid state NMR analyses were performed by means of ${ }^{13} \mathrm{C}$ CrossPolarization Magic Angle Spinning (CP MAS) NMR experiments. The ${ }^{13} \mathrm{C}$ CP MAS NMR spectrum of Pd@HCh-F exhibited a peak in the aliphatic region around $30 \mathrm{ppm}$, analogously to $\mathrm{HCh}$ $\mathbf{F}$, but not present for HCh-D; this resonance could be attributed to the $\mathrm{N}$-functionalization of the hydrochar (Figure 10).
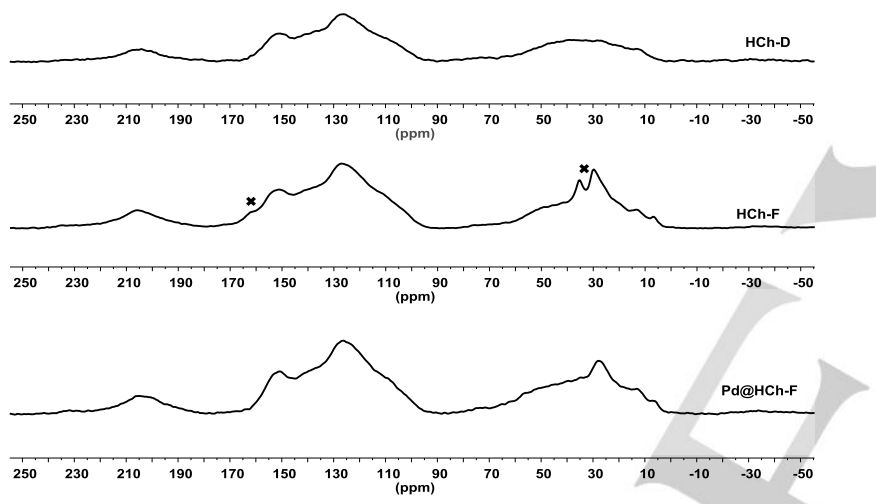

Figure 10. ${ }^{13} \mathrm{C}$ CP MAS NMR spectra of HCh-D, HCh-F, and Pd@HCh-F. denotes signals probably due to residual DMF adsorbed on the surface. ${ }^{[38]}$

Consequently, Pd@HCh-F was the selected material for catalytic studies; Pd@HCh-D (hydrochar bearing hydroxyl groups) and commercial Pd/C (10 mol\%) were used for control purposes.

\section{Pd-catalyzed hydrogenations}

In this study, we chose the hydrogenation of 1-phenyl-1-propyne as benchmark reaction, using both catalysts, Pd@HCh-D (ammonium-free support) and Pd@HCh-F (ammoniumfunctionalized support) under low $\mathrm{H}_{2}$ pressure (1 and $3 \mathrm{bar}$ ) and moderate temperature $\left(50^{\circ} \mathrm{C}\right)$, in the presence of $0.5 \mathrm{~mol} \% \mathrm{Pd}$ loading. Both systems gave full conversion under 3 bar $\mathrm{H}_{2}$ for 2 $\mathrm{h}$ (entries 1-2, Table 1). Under smoother conditions (1 $\mathrm{h}$ and 1 bar $\mathrm{H}_{2}$ pressure), Pd@HCh-F kept its activity, while Pd@HCh-D led to only $34 \%$ conversion (entries $3-4$, Table 1). High chemoand stereoselectivity towards the formation of the cis-alkene was obtained with both catalysts (entries 3-4, Table 1). TEM analyses after hydrogenation (entries 1-2, Table 1) evidenced clear differences between both catalytic materials: while Pd@HCh-F was not modified, Pd@HCh-D showed agglomeration (see Figure S5 in the Supporting Information), in accordance with the activity loss when Pd@HCh-D was recycled (entry 1, Table 1). In contrast to metal-based catalysts for the semihydrogenation of alkynes, ${ }^{[29 e, 39]}$ the catalytic behavior of Pd@HCh-D and Pd@HCh-F proved that the hydrochar supports did not passivate the palladium surface, thus favoring the adsorption of alkenes.

Table 1. Hydrogenation of 1-phenyl-1-propyne catalyzed by PdNP supported on functionalized hydrochars. ${ }^{a}$

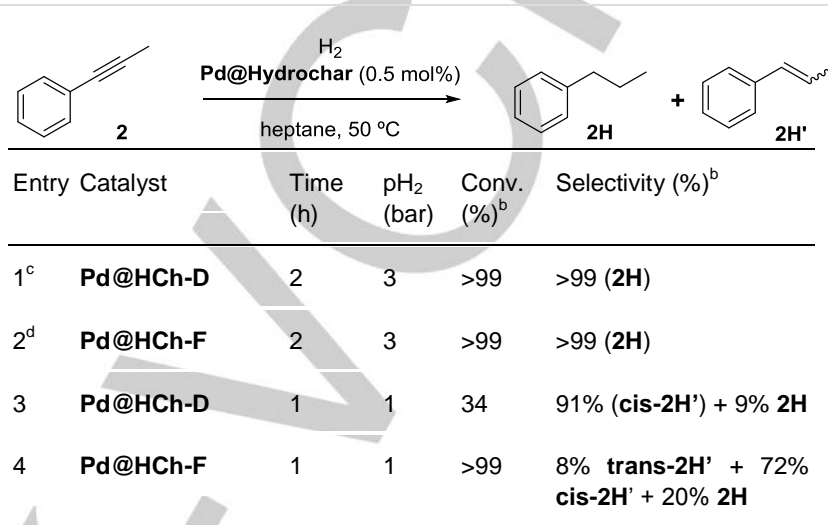

${ }^{a}$ Reaction conditions: $1 \mathrm{mmol}$ of 1-phenyl-1-propyne (2), $0.5 \mathrm{~mol} \%$ of $\mathrm{Pd}, 1$ $\mathrm{mL}$ of heptane at $50{ }^{\circ} \mathrm{C}$. ${ }^{\mathrm{b}}$ Determined by GC using dodecane as internal standard. ${ }^{\mathrm{C}}$ After the first run, TEM analysis evidenced the agglomeration of PdNPs (see Figure S5a in the Supporting Information); its recycling gave only $70 \%$ conversion. ${ }^{d}$ After the first run, PdNPs were not modified (see Figure $\mathrm{S} 5 \mathrm{~b}$ in the Supporting Information).

Then, we applied the most active catalyst, i.e. Pd@HCh-F, in the hydrogenation of di-, tri- and tetra-substituted alkenes under 1 bar $\mathrm{H}_{2}$ pressure (entries 1-4, Table 2). The cyclic conjugated alkene 3 led selectively to the corresponding hydrogenated compound $\mathbf{3} \mathbf{H}$, even at $0.1 \mathrm{~mol} \% \mathrm{Pd}$ (entry 1, Table 2). Internal alkenes are more challenging substrates; 2,3-dimethyl-but-2-ene (4) gave the reduced compound under higher pressure (3 bar $\mathrm{H}_{2}$; entry 2, Table 2). The geminal alkene 2,3-dimethyl-but-1-ene (5) mainly led to the isomerization product $(4,65 \%)$ together with 2,3-dimethylbutane (35\%) (entry 3, Table 2). In accordance to these results, the hydrogenation of $(R)$-limonene $((R)-6)$ mainly afforded the product corresponding to the hydrogenation of the exocyclic $\mathrm{C}=\mathrm{C}$ bond (entry 4 , Table 2 ).

4-Phenyl-3-buten-2-one (7) led selectively to the formation of 4phenylbutan-2-one $(\mathbf{7 H})$, a common skeleton present in fragrances (entry 5, Table 2). For this reaction, the catalyst was reused ten consecutive runs preserving its catalytic behavior (Figure 11); for all 10 runs, no palladium was detected by ICPAES for the extracted organic products (less than $0.05 \mathrm{ppm} P d$, limit of detection). TEM analyses after the $5^{\text {th }}$ and $10^{\text {th }}$ runs did not show any morphological change in relation to the starting catalytic material (see Figures S6 and S7 in the Supporting Information). Thus, the functionalization by grafting tetraalkylammonium groups via ether bond linkages allows the recyclability of the supported nanocatalyst Pd@HCh-F for hydrogenation processes.

The performance of $\mathbf{P d @ H C h - F}$ was benchmarked to commercial $\mathrm{Pd} / \mathrm{C}$. This commercial material gave quantitative conversions up to three recyclings under the same reaction conditions ( $50 \stackrel{\circ}{\circ} \mathrm{C}, 30 \mathrm{~min}$ and $0.5 \mathrm{~mol} \%$ catalyst loading), but the 
conversion decayed to $36 \%$ in the fourth cycle. The efficient recycling capabilities of Pd@HCh-F in comparison to Pd@HChD and commercial $\mathrm{Pd} / \mathrm{C}$ validate our mild functionalization strategy towards the design and synthesis of robust hydrocharsupported catalysts which could be of interest for other carbonaceous raw supports. ${ }^{[30,40]}$

Table 2. Pd@HCh-F catalyzed hydrogenation of different functional groups. ${ }^{a}$

Entry Substrate Product $\quad \mathrm{Pd} \quad \mathrm{t} \quad \mathrm{pH}_{2} \quad$ Conv. Selectivity
$(\mathrm{mol} \%) \quad(\mathrm{h}) \quad(\mathrm{bar}) \quad(\%)^{\mathrm{b}} \quad(\%)^{\mathrm{b}, \mathrm{c}}$

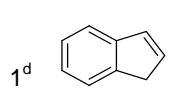<smiles>CC(C)=C(C)C</smiles>

4<smiles>C=C(C)C(C)C</smiles><smiles>C=C(C)C1CC=C(C)CC1</smiles>

$(R)-6$

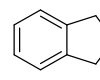

$3 \mathrm{H}$<smiles>CC(C)C(C)C</smiles>

0.5

$4 \mathrm{H}$<smiles>CC(C)C(C)C</smiles>

$4 \mathrm{H}$<smiles>CC1=CCC(C(C)C)CC1</smiles>

$6 \mathrm{H}$

$\begin{array}{lllll}0.5 & 1 & 1 & >99 & 100 \\ (0.1) & (1) & (1) & (98) & (100)\end{array}$

$3 \quad 50$

$50 \quad 100$

$0.5 \quad 1 \quad 3 \quad>99 \quad 35(4 \mathrm{H})$

$65(4)$ as internal standard. ${ }^{\dagger}$ Menthane and isomerization products of menthene were also detected. ${ }^{9}$ after $6 \mathrm{~h} .{ }^{\mathrm{h}}$ after $15 \mathrm{~h}$.

With the aim of proving the high activity of Pd@HCh-F, we studied the hydrogenation of a tetrasubstituted compound, 1,2,3,4,5-pentamethylcyclopentadiene (entry 6, Table 2). At short time ( $1 \mathrm{~h}$ under 3 bar $\mathrm{H}_{2}$ ), 49\% conversion was achieved leading exclusively to 1,2,3,4,5-pentamethylcyclopentene. The catalyst was recycled and reused under the same conditions but at longer times, giving full conversion after $15 \mathrm{~h}$ of reaction (after $6 \mathrm{~h}$ of reaction, $90 \%$ conversion was attained). These results show that this catalytic system only hydrogenates conjugated tetrasubstituted alkenes.

Exploration of the hydrogenation substrate scope Pd@HCh-F revealed that both nitro and aldehyde groups can be reduced under mild reaction conditions. In particular, benzaldehyde ( $\mathbf{9}$, entry 7, Table 2) and nitrobenzene derivatives (10 and 11, entries 8-9, Table 2) were efficiently reduced; for 11, no hydrodehalogenation was observed under these reaction conditions. However, acetophenone and indole were not hydrogenated by Pd@HCh-F even under harsher conditions (40 bar $\mathrm{H}_{2}$ and $50^{\circ} \mathrm{C}$ for $16 \mathrm{~h}$ ).
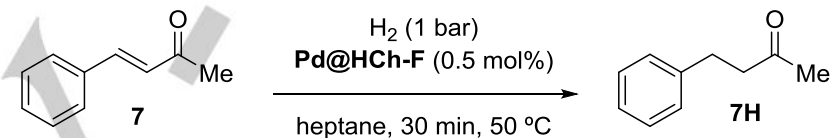

$\begin{array}{lllll}0.5 & 1 & 3 & >99 & 85(6 \mathrm{H})^{\dagger}\end{array}$

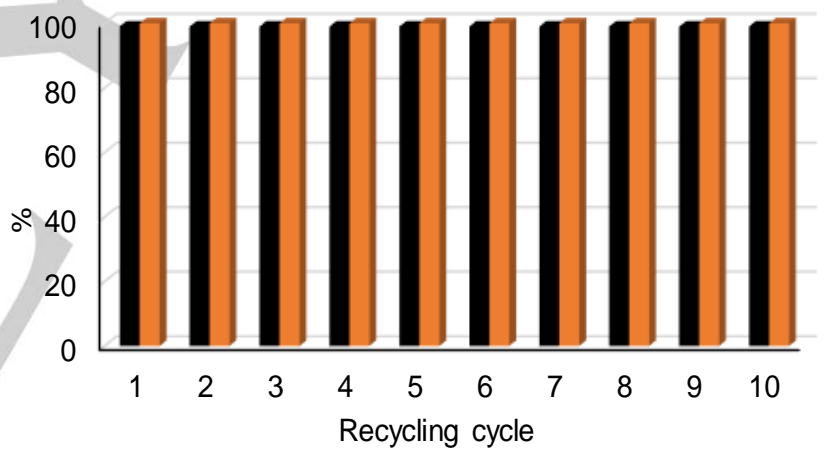

- Conversion 4-phenyl-2-butanone selectivity

Figure 11. Recycling of hydrogenation of 4-phenyl-3-buten-2-one catalyzed by Pd@HCh-F

The slower hydrogenation of aldehydes compared to nitro groups permitted to carry out a reductive amination in one pot procedure starting from nitrobenzene and benzaldehyde to yield $\mathrm{N}$-benzylaniline (11) in 57\% isolated yield (Figure 12). The reaction proceeds via condensation of the formed aniline with the unreacted aldehyde to form the corresponding benzylideneaniline which undergoes hydrogenation much easily than the parent aldehyde. Reaction by-products arising from reduction of the aldehyde [i.e. aniline (32\%), the condensation intermediate (phenylmethylidene)aniline $(8 \%)$, and also benzyl alcohol (9\%)], were detected by ${ }^{1} \mathrm{H}$ NMR. The reaction conditions were not further optimized.

\footnotetext{
a Reaction conditions: $1 \mathrm{mmol}$ of substrate, $1 \mathrm{~mL}$ of heptane at $50{ }^{\circ} \mathrm{C}$ using Pd@HCh-F as catalyst. ${ }^{b}$ Determined by GC-MS analyses using dodecane as internal standard. ${ }^{\mathrm{c}}$ Characterization of the product by NMR. ${ }^{\mathrm{d}}$ Data in brackets correspond to $0.1 \mathrm{~mol} \%$ catalyst loading. ${ }^{\mathrm{e}}$ Dodecane as solvent and heptane
} 

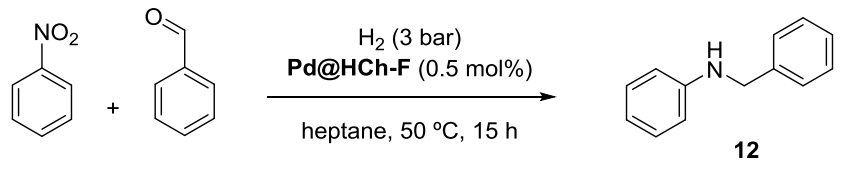

$>99 \%$ conv.

( $57 \%$ isolated yield)

Figure 12. Pd@HCh-F catalyzed one-pot reductive amination.

\section{Conclusion}

With the aim of synthesizing selectively functionalized hydrochar supports derived from a naturally occurring sugar (sucrose), a thermal treatment of HCh-A and HCh-B precursors afforded enriched carbonaceous materials with hydroxyl groups exhibiting no traces of carboxylic acids on the surface, together with little to negligible porosity properties. Taking advantage of the chemical stability of the ether bond linkages, a series of functionalized tetraalkylammonium hydrochars were prepared enabling a comparative study towards the use of these materials as both supports and stabilizers for the synthesis of palladium nanoparticles. The ammonium groups prompted an electrostatic stabilization and in consequence an efficient adsorption of the metal nanoparticles on the hydrochars.

These catalytic materials were straightforwardly prepared in a one-pot procedure, by in-situ reduction of $\mathrm{Pd}(\mathrm{OAc})_{2}$ in the presence of the corresponding support under hydrogen atmosphere. Among these as-prepared materials, Pd@HCh-D and Pd@HCh-F were chosen for catalytic evaluation due to the exhibited stability of supports during the synthesis of the catalytic materials (as evidenced by SEM analyses). These heterogeneous catalysts were tested in the hydrogenation of different unsaturated functional groups, revealing high selectivity Pd@HCh-F was highly efficient towards the full hydrogenation of alkyne and alkene substrates under mild conditions. Moreover, aldehyde and nitro groups were also hydrogenated. The enhanced recyclability of Pd@HCh-F was proven, being reused 10 consecutive runs preserving the catalytic reactivity; no metal leaching was detected in the extracted organic phases. Under the same reaction conditions, the activity of commercial $\mathrm{Pd} / \mathrm{C}$ decayed after the third catalyst recycling, giving only a $36 \%$ conversion in the fourth run.

Overall, the low porosity of HCh-D and derived hydrochars might help against deleterious diffusion pathways through the catalyst support itself, thus enabling milder reaction conditions than for micro- and mesoporous catalytic materials. ${ }^{[12 a, 12 c]}$ In contrast to unfunctionalized supports such as Pd@HCh-D and those reported in the literature, ${ }^{[30,}{ }^{40]}$ tetraalkylammonium functionalization enables the recyclability of the catalytic material Pd@HCh-F mainly thanks to the robustness of the support and Pd-support electrosteric interactions.

\section{Experimental Section}


were characterized by Transmission Electron Microscopy (TEM). Pd@HCh-D and Pd@HCh-F were further characterized by different techniques (see section 3): solid state Nuclear Magnetic Resonance (ssNMR), elemental analysis, SEM, FTIR, Raman, XPS, and ICP-AES.

\section{Pd-catalyzed hydrogenation reactions}

Substrate $(1 \mathrm{mmol})$ in $1 \mathrm{~mL}$ of heptane and in the presence of $0.5 \mathrm{~mol} \%$ Pd of the corresponding catalytic material (Pd@HCh-D, Pd@HCh-F) was pressurized at the convenient pressure (from 1 to 40 bar) and temperature, and stirred for the appropriate time. After depressurization and cooling down at room temperature, the liquid phase was recovered by micro-filtration and the catalytic material washed with heptane $(3 \times 1$ $\mathrm{mL}$ ). The combined heptane fractions were evaporated under reduced pressure and the organic products were analyzed by Gas Chromatography coupled Mass Spectrometry (GC-MS) and ${ }^{1} \mathrm{H}$ NMR, using dodecane as internal standard, unless otherwise stated.

Despite the different porosity characteristics (specific surface area of 759 $\mathrm{m}^{2} \mathrm{~g}^{-1}$ and total pore volumes of 0.23 and $\left.0.31 \mathrm{~cm}^{3} \mathrm{~g}^{-1}\right),{ }^{[34]}$ palladium supported on activated carbon ( $\mathrm{Pd} / \mathrm{C}, 10 \mathrm{~mol} \%)$ was tested as catalyst control.

\section{Catalytic recycling}

The catalyst was recovered after hydrogenation by filtration, washed with heptane $(5 \times 10 \mathrm{~mL})$ and dried under vacuum for $2 \mathrm{~h}$ before to be used in the subsequent hydrogenation reaction.

\section{Acknowledgements}

The Centre National de la Recherche Scientifique (CNRS) and the Université de Toulouse 3 - Paul Sabatier are gratefully acknowledged for their financial support. The work was also supported by the Foundation for Science and Technology (FCT) through projects UID/Multi/00612/2019 to Centro de Química e Bioquímica, UID/QUI/00100/2019 and PTDC/QEQ$\mathrm{ERQ} / 1648 / 2014$ and CATSUS PhD fellowship (PD/BD/105993/2014) to T. A. G. D. The authors thank Yannick Coppel for helpful discussions concerning the solid state NMR studies, and S. Mallet-Ladeira and L. Vendier for X-ray diffraction analyses.

Keywords: Hydrochar, Palladium nanoparticles, Hydrogenation, Support functionalization, Recycling.

[1] A. Reina, A. Serrano-Maldonado, E. Teuma, E. Martin, M. Gómez, Catal. Commun. 2018, 104, 22.

[2] a) I. Favier, D. Pla, M. Gómez, Chem. Rev. 2019, doi 10.1021/acs.chemrev.9b00204; b) A. Bouriazos, C. Vasiliou, A. Tsichla, G. Papadogianakis, Catal. Today 2015, 247, 20; c) S. Bulut, Z. Fei, S. Siankevich, J. Zhang, N. Yan, P. J. Dyson, Catal. Today 2015, 247, 96; d) D. J. Gavia, Y.-S. Shon, ChemCatChem 2015, 7, 892; e) M. R. Knecht, D. B. Pacardo, Anal. Bioanal. Chem. 2010, $397,1137$.

[3] a) A. B. Dongil, L. Pastor-Perez, J. L. G. Fierro, N. Escalona, A. Sepulveda-Escribano, Appl. Catal., A 2016, 513, 89; b) K. Duan, Z Wang, C. Hardacre, Z. Liu, S. Chansai, C. Stere, Catal. Today 2019, 332, 69; c) G. C. Mondragon Rodriguez, B. Saruhan, O. Petrova, W Gruenert, Top. Catal. 2009, 52, 1723; d) M. Y. Smirnov, E. I. Vovk, A V. Kalinkin, A. V. Pashis, V. I. Bukhtiyarov, Kinet. Catal. 2012, 53, 117.

[4] T. Kahl, K. Schröder, F. R. Lawrence, W. J. Marshall, H. Höke, R. Jäckh, in Ullmann's Encyclopedia of Industrial Chemistry, 2011.
[5] a) B. Hosseinkhani, T. Hennebel, S. Van Nevel, S. Verschuere, M. M. Yakimov, S. Cappello, M. Blaghen, N. Boon, Environ. Sci. Technol. 2014, 48, 550; b) M. M. Khin, A. S. Nair, V. J. Babu, R Murugan, S. Ramakrishna, Energy Environ. Sci. 2012, 5, 8075; c) B.-Z. Wu, H.-Y. Chen, S. J. Wang, C. M. Wai, W. Liao, K. Chiu, Chemosphere 2012, 88, 757; d) B. Kumari, D. P. Singh, Ecol. Eng. 2016, 97, 98

[6] J. Bassil, A. AlBarazi, P. Da Costa, M. Boutros, Catal. Today 2011, 176, 36

[7] A. Balanta, C. Godard, C. Claver, Chem. Soc. Rev. 2011, 40, 4973

[8] a) T. Dang-Bao, D. Pla, I. Favier, M. Gómez, Catalysts 2017, 7, 207; b) J. D. Scholten, B. C. Leal, J. Dupont, ACS Catal. 2012, 2, 184; c) C. Janiak, in Ionic Liquids (ILs) in Organometallic Catalysis (Eds.: J. Dupont, L. Kollár), Springer Berlin Heidelberg, Berlin, Heidelberg, 2015, pp. 17

[9] a) S. Noël, B. Léger, A. Ponchel, K. Philippot, A. DenicourtNowicki, A. Roucoux, E. Monflier, Catal. Today 2014, 235, 20; b) A Denicourt-Nowicki, A. Roucoux, in Nanomaterials in Catalysis (Eds. P. Serp, K. Philippot), Wiley-VCH Verlag GmbH \& Co. KGaA, Weinheim, 2013, pp. 55; c) J. Yang, J. Y. Lee, J. Y. Ying, Chem. Soc. Rev. 2011, 40, 1672.

[10] a) A. Reina, C. Pradel, E. Martin, E. Teuma, M. Gómez, RSC Adv. 2016, 6, 93205; b) F. Fiévet, S. Ammar-Merah, R. Brayner, F. Chau, M. Giraud, F. Mammeri, J. Peron, J. Y. Piquemal, L. Sicard, G. Viau, Chem. Soc. Rev. 2018, 47, 5187.

[11] a) G. Budroni, A. Corma, H. García, A. Primo, J. Catal. 2007, 251, 345; b) B. Karimi, M. Khorasani, H. Vali, C. Vargas, R. Luque ACS Catal. 2015, 5, 4189

[12] a) S. Mandal, D. Roy, R. V. Chaudhari, M. Sastry, Chem. Mater 2004, 16, 3714; b) M. Navlani-García, M. Martis, D. Lozano-Castelló, D. Cazorla-Amorós, K. Mori, H. Yamashita, Catal. Sci. Technol. 2015, 5, 364; c) J. Zhang, L. Wang, Y. Shao, Y. Wang, B. C. Gates, F. S. Xiao, Angew. Chem., Int. Ed. 2017, 56, 9747.

[13] D. Divakar, D. Manikandan, V. Rupa, E. L. Preethi, R Chandrasekar, T. Sivakumar, J. Chem. Technol. Biotechnol. 2007, 82, 253.

[14] a) H. P. Hemantha, V. V. Sureshbabu, Org. Biomol. Chem. 2011, 9, 2597; b) V. L. Budarin, J. H. Clark, R. Luque, D. J. Macquarrie, R. J. White, Green Chem. 2008, 10, 382.

[15] a) L. Chen, H. Chen, R. Luque, Y. Li, Chem. Sci. 2014, 5, 3708; b) J. Hermannsdörfer, R. Kempe, Chem. Eur. J. 2011, 17, 8071.

[16] S.-F. Jiang, L.-L. Ling, Z. Xu, W.-J. Liu, H. Jiang, Ind. Eng Chem. Res. 2018, 57, 13055

[17] X. Sun, Y. Li, Angew. Chem., Int. Ed. 2004, 43, 597.

[18] a) B. Cornelio, G. A. Rance, M. Laronze-Cochard, A. Fontana, J. Sapi, A. N. Khlobystov, J. Mater. Chem. A 2013, 1, 8737; b) B. Cornelio, A. R. Saunders, W. A. Solomonsz, M. Laronze-Cochard, A. Fontana, J. Sapi, A. N. Khlobystov, G. A. Rance, J. Mater. Chem. A 2015, 3, 3918.

[19] S. Sadjadi, M. Akbari, B. Léger, E. Monflier, M. M. Heravi, ACS Sustainable Chem. Eng. 2019, 7, 6720.

[20] a) M. Nasrollahzadeh, S. Mohammad Sajadi, A. RostamiVartooni, M. Alizadeh, M. Bagherzadeh, J. Colloid Interface Sci. 2016, 466, 360; b) S. I. El-Hout, S. M. El-Sheikh, H. M. A. Hassan, F. A. Harraz, I. A. Ibrahim, E. A. El-Sharkawy, Appl. Catal., A. 2015, 503,176

[21] Y. Chen, X. Ai, B. Huang, M. Huang, Y. Huang, Y. Lu, Cellulose 2017, 24, 2743.

[22] Y. Chen, J. Chen, S. Chen, K. Tian, H. Jiang, J. Mater. Chem. A 2015, 3, 9843 .

[23] J. Vieillard, N. Bouazizi, R. Bargougui, N. Brun, P. Fotsing Nkuigue, E. Oliviero, O. Thoumire, N. Couvrat, E. Djoufac Woumfo, G. Ladam, N. Mofaddel, A. Azzouz, F. Le Derf, Chem. Eng. J. 2018, 342,420 .

[24] a) N. Tran Hai, F.-C. Huang, C.-K. Lee, H.-P. Chao, Green Process. Synth. 2017, 6, 565; b) H. Wang, L. Ma, K. Cao, J. Geng, J. Liu, Q. Song, X. Yang, S. Li, J. Hazard. Mater. 2012, 229-230, 321; c) D.-P. Yang, Z. Li, M. Liu, X. Zhang, Y. Chen, H. Xue, E. Ye, R. Luque, ACS Sustainable Chem. Eng. 2019, 7, 4564.

[25] A. Dieguez-Alonso, A. Funke, A. Anca-Couce, A. Rombolà, G. Ojeda, J. Bachmann, F. Behrendt, Energies 2018, 11, 496.

[26] Y. Shi, T. Zhang, H. Ren, A. Kruse, R. Cui, Bioresour Technol. 2018, 247, 370. 
[27] a) H. Choi, S. R. Al-Abed, S. Agarwal, D. D. Dionysiou, Chem. Mater. 2008, 20, 3649; b) F. He, D. Zhao, Environ. Sci. Technol. 2005, 39, 3314.

[28] a) M. Nunes, I. M. Rocha, D. M. Fernandes, A. S. Mestre, C. N. Moura, A. P. Carvalho, M. F. R. Pereira, C. Freire, RSC Adv. 2015, 5, 102919; b) D. M. Fernandes, A. S. Mestre, A. Martins, N. Nunes, A. P. Carvalho, C. Freire, Catal. Today 2019, doi: 10.1016/j.cattod.2019.02.048; c) A. S. Mestre, E. Tyszko, M. A. Andrade, M. Galhetas, C. Freire, A. P. Carvalho, RSC Adv. 2015, 5, 19696.

[29] a) L. Rodríguez-Pérez, E. Teuma, A. Falqui, M. Gómez, P. Serp, Chem. Commun. 2008, 4201; b) E. Castillejos, M. Jahjah, I. Favier, A. Orejon, C. Pradel, E. Teuma, A. M. Masdeu-Bulto, P. Serp, M. Gómez, ChemCatChem 2012, 4, 118; c) I. Favier, M.-L. Toro, P. Lecante, D. Pla, M. Gómez, Catal. Sci. Technol. 2018, 8, 4766; d) F. Chahdoura, C. Pradel, M. Gómez, Adv. Synth. Catal. 2013, 355, 3648; e) A. Reina, I. Favier, C. Pradel, M. Gómez, Adv. Synth. Catal. 2018, 360, 3544; f) T. Dang-Bao, C. Pradel, I. Favier, M. Gómez, Adv. Synth. Catal. 2017, 359, 2832.

[30] a) C. W. A. Chan, Y. Xie, N. Cailuo, K. M. K. Yu, J. Cookson, P. Bishop, S. C. Tsang, Chem. Commun. 2011, 47, 7971; b) P. Burguete, A. Corma, M. Hitzl, R. Modrego, E. Ponce, M. Renz, Green Chem. 2016, 18, 1051.

[31] T. A. G. Duarte, A. P. Carvalho, L. M. D. R. S. Martins, Catal. Today 2019, doi: 10.1016/j.cattod.2019.04.044.

[32] J. Clayden, N. Greeves, S. Warren, Organic Chemistry, OUP Oxford, 2012.

[33] a) T. J. Bandosz, C. O. Ania, in Interface Science and Technology, Vol. 7 (Ed.: T. J. Bandosz), Elsevier, 2006, pp. 159; b) $\mathrm{H}$. Marsh, F. Rodríguez-Reinoso, in Activated Carbon, Elsevier Science Ltd, Oxford, 2006; c) J. L. Figueiredo, M. F. R. Pereira, M. M. A. Freitas, J. J. M. Órfão, Carbon 1999, 37, 1379.

[34] M. Thommes, K. Kaneko, A. V. Neimark, J. P. Olivier, F. Rodriguez-Reinoso, J. Rouquerol, K. S. Sing, Pure Appl. Chem. 2015, 87, 1051.

[35] E. Pretsch, P. Bühlmann, M. Badertscher, Structure Determination of Organic Compounds: Tables of Spectral Data, Springer Berlin Heidelberg, 2009.

[36] J. Durand, E. Teuma, M. Gómez, Eur. J. Inorg. Chem. 2008, 2008, 3577.

[37] T. Reed, J. Fournier, G. Nelson, Raman Characterization of Biochar Bonding, 2009. https://www.peaklab.net/peaklabreports/raman-characterization-of-biochar-bonding/.

[38] The use of cross-polarization excitation techniques ${ }^{13} \mathrm{C}$ CP MAS permits to suppress signals from solvent molecules due to their relative mobility properties. However, signals of adsorbed DMF cannot be excluded.

[39] a) v. H. Lindlar, Helv. Chim. Acta 1952, 35, 446; b) P. T. Witte, P. H. Berben, S. Boland, E. H. Boymans, D. Vogt, J. W. Geus, J. G. Donkervoort, Top. Catal. 2012, 55, 505; c) P. Gallois, J. J. Brunet, P. Caubere, J. Org. Chem. 1980, 45, 1946; d) D. Savoia, E. Tagliavini, C. Trombini, A. Umani-Ronchi, J. Org. Chem. 1981, 46, 5340; e) M. Zhao, Chem. Asian J. 2016, 11, 461.

[40] M. Oregui-Bengoechea, N. Miletić, W. Hao, F. Björnerbäck, M. H. Rosnes, J. S. Garitaonandia, N. Hedin, P. L. Arias, T. Barth, ACS Sustain. Chem. Eng. 2017, 5, 11226.

[41] R. Demir-Cakan, N. Baccile, M. Antonietti, M.-M. Titirici, Chem. Mater. 2009, 21, 484. 


\section{Entry for the Table of Contents}

Tetraalkylammonium functionalized hydrochars as efficient supports for palladium nanocatalysts.

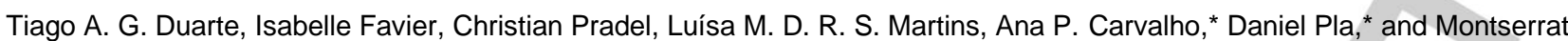
Gómez*

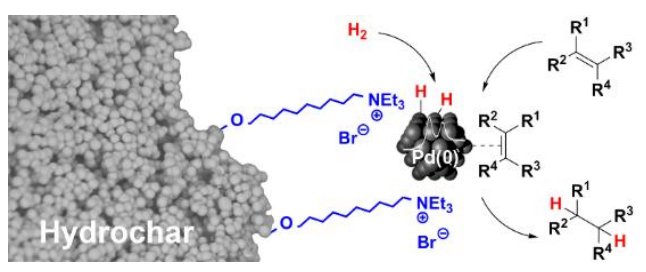

Tetraalkylammonium-functionalized hydrochars outperform classical Pd on carbon supports for catalyst heterogenization in terms of morphology-controlled palladium nanoparticle synthesis, efficient immobilization and recyclability towards hydrogenation.

Twitter: https://twitter.com/cat_tlse 